\title{
Implementasi Smart Router Berbasis OpenWRT Sebagai Media Untuk File Sharing dan Chatting Pada Laboratorium Terpadu Unmuh Jember
}

\author{
Triawan Adi Cahyanto' ${ }^{1)}$, Irfan Samsu Nurhuda ${ }^{2)}$ \\ ${ }^{1,2)}$ Program Studi Teknik Informatika, Fakultas Teknik, Universitas Muhammadiyah Jember \\ Email: ${ }^{1}$ triawanac@ unmuhjember.ac.id, ${ }^{2}$ blackhiden@ gmail.com
}

\begin{abstract}
Perkembangan teknologi perangkat keras seperti router, server, dan perangkat lain mempermudah seorang pengguna dalam membuat suatu perangkat khusus untuk menangani kebutuhan pengguna pada suatu instansi. Namun, kekurangan dari server khusus untuk membuat perangkat khusus untuk file sharing dan chatting masih belum terjangkau oleh semua lapisan masyarakat. Oleh karena itu, maka perlu dibangun sistem yang memiliki fitur yang sama dengan hardware server tersebut dengan hardware router yang harganya lebih terjangkau. Penggunaan sistem yang diembbed ke hardware router dibangun memanfaatkan sistem operasi OpenWRT. OpenWRT yang nantinya dipasang pada router akan ditambahkan dengan media penyimpanan flashdisk, harddisk external, dan usb hub untuk menyimpan data. Sistem yang dihasilkan akan memiliki kemampuan berinteraksi dengan pengguna, selama penggunaannya masih ada di ruang lingkup Laboratorium Terpadu Gedung CC Universitas Muhammadiyah Jember baik menggunakan kabel maupun WiFi.
\end{abstract}

Keyword: Wireless Router, OpenWRT, File Sharing, Chatting

\section{PENDAHULUAN}

Jaringan komputer merupakan suatu himpunan interkoneksi sejumlah komputer dalam ruang lingkup tertentu maupun dalam jumlah tertentu [1]. Konsep dari bidang ilmu jaringan komputer merupakan kumpulan beberapa komputer dan perangkat lain (printer, scanner, hub, dan lain-lain) yang saling terhubung satu sama lain melalui media perantara [2]. Media perantara dapat berupa media kabel maupun media tanpa kabel (nirkabel) [3]. Perkembangan perangkat keras saat ini sudah mengarah ke fleksibilitas penggunaan, dimana media kabel sudah mulai kalah saing dengan munculnya berbagai perangkat keras menggunakan media nirkabel [4]. Berawal dari munculnya perangkat keras mikrotik beserta lisensi sistem operasi, kemudian pabrik pengembang perangkat keras membuat perangkat keras serupa beserta firmware didalam perangkatnya [5]. Salah satu perangkat keras yang menggunakan media nirkabel yaitu router. Penggunaan router dengan media nirkabel dapat berfungsi sebagai access point, captive portal, bandwidth management, dan masih banyak yang lain [6]-[9]. Berdasarkan keterangan tersebut, peneliti akan mencoba untuk mengimplementasikan wireless router agar menjadi Smart Router yang dapat berfungsi sebagai media file sharing dan chatting. Wireless router yang dipakai menggunakan TP-Link MR-3020 karena perangkat keras tersebut memiliki bentuk yang simpel, ringan dan mempunyai daya yang rendah. Penggunaan wireless router ini diharapkan dapat membantu kelancaraan dalam berkomunikasi pada laboratorium terpadu Universitas Muhammadiyah Jember [10]. Selain dapat digunakan sebagai access point, penggunaan perangkat ini juga efisien biaya karena harga perangkat yang murah dan konsumsi listrik yang dibutuhkan rendah.

\section{Metode Penelitian}

Tahapan yang dilakukan dalam penelitian ini adalah

- Studi Literatur

Sebelum penelitian dimulai, akan dilakukan studi literatur terlebih dahulu terkait dengan sistem yang akan dibangun. Selain itu, analisis kebutuhan juga dirancang pada tahap ini.

- Perancangan Aplikasi

Dalam tahap ini, akan dilakukan perancangan aplikasi yang akan dibangun dan hasilnya berupa dokumentasi yang berisi fitur-fitur aplikasi dan diagram arsitektur sistem.

- Pengembangan Aplikasi

Dalam tahap ini, dilakukan pengembangan aplikasi yang sudah dirancang dalam tahap sebelumnya. Aplikasi dikembangkan dengan alat dan tools yang sudah disiapkan.

- Evaluasi dan Perbaikan

Dalam tahap ini, aplikasi yang telah dibuat akan dievaluasi bagaimana kinerja dan apa saja bug-bug yang ada. Setelah evaluasi dilakukan, perbaikan terhadap aplikasi akan dievaluasi lagi.

\section{DiAgRAM ALIR PENELITIAN}

Diagram alir penelitian yang menjelaskan tentang alur pekerjaan dalam penelitian ini dapat dilihat pada gambar 1 berikut ini: 


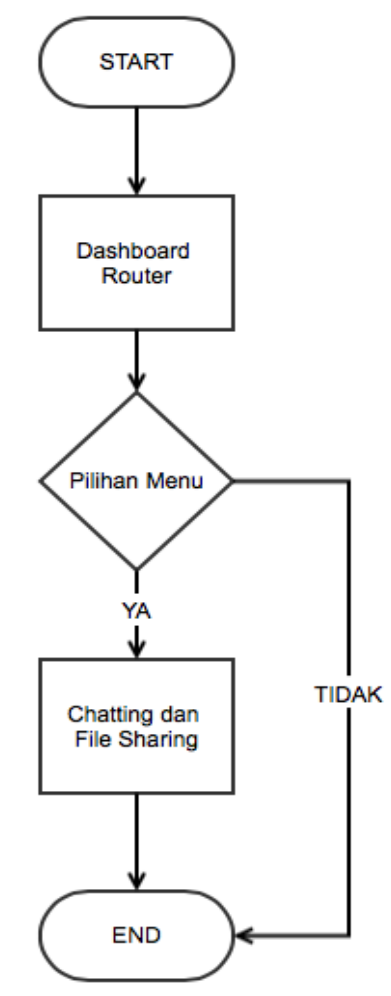

Gambar 1: Diagram Alir Penelitian

Diagram alir penelitian diatas menjelaskan gambaran keseluruhan dari sistem yang akan dibangun. Dashboard router merupakan proses yang diperoleh ketika pengguna dapat mengakses sistem melalui router. Apabila berhasil masuk dengan benar, maka sistem akan menyajikan dua fungsi utama yaitu file sharing dan chatting.

\section{Metode Pengembangan Sistem}

Metode pengembangan sistem pada penelitian ini mengacu pada metode SDLC (System Development Life Cycle), dengan menggunakan model waterfall atau Model Sekuensial Linier [11]. Metode Waterfall memiliki beberapa proses antara lain:

- Analisis

Tahap analisis ini dimaksudkan untuk memperoleh garis besar gambaran dari sistem yang akan dibangun. Analisis meliputi keunggulan sistem ini jika dibandingkan dengan perangkat yang lain, konsep dari file sharing dan chatting itu sendiri dan juga konfigurasi hardware yang dibangun.

- Perancangan

Untuk perancangan sistem digunakan flowchart atau diagram alir untuk memperlihatkan langkah-langkah setiap proses yang terjadi pada sistem. Pada tahap ini juga dilakukan perancangan untuk desain antarmuka sistem.

- Implementasi

Pada tahap ini, hasil perancangan sistem maupun perancangan antarmuka akan diimplementasikan dengan menggunakan PHP.
- Pengujian

Metode pengujian dilakukan untuk mengetahui apakah sistem yang dibangun sudah berjalan sesuai rencana awal atau belum. Didalam pengujian ini, penulis menggunakan metode Alpha dan Beta testing dengan keterangan sebagai berikut:

a. Alpha testing

Pengujian Alpha testing digunakan untuk menguji fungsionalitas dari sistem.

b. Beta Testing

Pengujian Betatesting dilakukan secara objektif dengan menyebar kuisioner kepada responden dengan latar belakang berbeda. Pengujian ini digunakan untuk mengetahui kelebihan dan kekurangan interface pada sistem.

- Pemeliharaan

Tahap pemeliharaan sistem merupakan tahap terakhir dalam metode waterfall. Pada tahap ini, dilakukan pemeliharaan sistem secara korektif atau dengan melakukan perbaikan pada kesalahan yang terjadi pada sistem.

\section{HASIL DAN IMPLEMENTASI}

\section{A. Gambaran Umum Sistem}

Sistem yang akan dibangun merupakan sebuah alternatif baru yang diharapkan dapat menjadi kombinasi yang hebat, antara hardware dengan software yang di-embedd didalam perangkat kerasnya. Sistem ini dibangun secara embedded pada sebuah router dengan sistem operasi OpenWRT, dengan begitu maka sistem ini akan lebih ringkas dan praktis jika dibandingkan dengan sistem yang sudah pernah ada.

Keunggulan lain dari sistem yang akan dibangun ini adalah kemudahan dalam mengakses dan mengontrol sistem. Antarmuka yang dibangun berbasis web akan memudahkan pengguna karena dapat diakses menggunakan komputer, laptop, tablet maupun handphone. Adanya fitur wireless dan akses langsung dari internet akan memudahkan pengguna dalam berkomunikasi dan berbagi file secara lokal. Sistem ini memiliki beberapa keunggulan seperti:

- Auto refresh halaman

- Tampilan halaman chatting yang user friendly

- Perangkat dapat dipindah-pindah dan diganti space media penyimpanan sesuai dengan kebutuhan

Router akan bertugas sebagai alat kontrol terhadap fungsifungsi alat dibawahnya yang terbagi menjadi beberapa modul. Modul storage dengan alat USB Flash Drive sebagai penyimpan berkas yang diunggah dan dibagi-bagikan kepada para pengguna. Modul USB Hub digunakan untuk menambahkan perangkat lain melalui tambahan port USB, sehingga router dapat fleksibel sesuai dengan kegunaan. Sedangkan akses ke router dapat dilakukan melalui 3 cara yaitu menggunakan kabel $L A N$, jaringan wifi, dan internet. 
B. Desain Sistem

Menu Header

Sub

Menu

Gambar 2: Desain Sistem

Keterangan Gambar :

- Menu header merupakan fitur yang terdapat pada sistem yang terdiri dari menu-menu utama yang berisi semua kebutuhan fungsional sistem.

- Halaman utama aplikasi merupakan halaman yang akan menampilkan fitur utama dari layanan router yaitu file sharing atau chatting.

- Sub menu merupakan tampilan sub menu utama dari sistem.

\section{Instalasi Sistem}

Piratebox merupakan firmware yang digunakan sebagai firmware yang akan digunakan pada router TP-Link MR3020. Penggunaan piratebox pada router digunakan sebagai firmware yang dapat menangani file sharing secara offline dan lokal, sehingga memungkin pengguna untuk saling berbagi pakai.

Berikut ini merupakan langkah-langkah instalasi piratebox:

- Siapkan firmware piratebox yang dapat diunduh dari website resmi piratebox.

- Hubungkan USB flash drive (flashdisk) ke USB port di komputer. Flashdisk harus diformat terlebih dahulu menjadi FAT32 dan dipartisi menjadi satu partisi.

- Pindahkan firmware squashfs-factory.bin ke flashdisk kemudian cabut dari komputer.

- Hubungkan flashdisk ke port USB yang terdapat pada router.

- Setting alamat IP address komputer agar sesuai dengan router, dimana IP address router adalah 192.168.1.1.

- Agar terhubung dengan router dapat menggunakan telnet atau ssh.

- Buka folder /mnt/usb dengan cara:

$c d / m n t / u s b$

- Install versi OpenWRT dan Piratebox 1.0 dengan cara:

sysupgrade - $n$ openwrt $\langle T A B\rangle$

$m t d$ write $-r$ openwrt $\langle T A B>$ firmware
- Apabila sudah selesai, router akan restart sebanyak dua kali.

- Matikan router dan ambil flashdisk kemudian hubungkan ke komputer anda.

- Ekstrak file install_piratebox.zip dan drag folder install ke USB flash drive anda.

- Cabut flashdisk dari komputer dan kemudian hubungkan flashdisk ke OpenWRT router anda.

- Hidupkan router, kemudian router akan melakukan instalasi paket yang dibutuhkan oleh firmware OpenWRT.

- Apabila instalasi sudah selesai, maka dapat menggunakan telnet untuk terhubung ke router dengan perintah berikut:

telnet 192.168.1.1.

\section{Konfigurasi Sistem}

Pada proses instalasi diatas, firmware piratebox belum berfungsi secara penuh sebagai firmware yang dapat digunakan sebagai file sharing dan chatting. Untuk mengoptimalisasikan penggunaan firmware tersebut, dibutuhkan konfigurasi sederhana terhadap firmware piratebox.

Berikut ini merupakan langkah-langkah yang diujicobakan:

- Pastikan dapat terhubung dengan router baik melalui ssh maupun telnet.

- Jalankan perintah berikut untuk mengaktifkan simple setup menu.

box_init_setup.sh

- Aktifkan "timesave functionality" pilih nomor 2 dan masukkan tanggal dan jam saat ini.

- Aktifkan kareha image dan discussionboard menggunakan perintah vi, dan ubah defaultusername dan passwordnya (default nya: username admin, password ADMIN_PASS dan SECRET).

- Hilangkan tanda \# yang terdapat pada baris konfigurasi dibawah ini:

\section{vi /opt/piratebox/www/board/config.pl}

- Aktifkan kareha melalui browser dengan cara mengetikkan:

\section{http://piratebox.lan/board/kareha.pl}

- Kembali ke mode ssh, kemudian aktifkan UPnP Media Server yang nantinya digunakan sebagai media file sharing, dengan cara sebagai berikut:

cp /opt/piratebox/src/openwrt.example.minidlna /mnt/ext/etc/config/minidlna

- Untuk mengubah nama MediaServer dapat mengubah dengan perintah berikut ini:

vi /etc/config/minidlna 
- Jalankan media server dengan cara sebagai berikut:

letc/init.d/minidlna start

letc/init.d/minidlna enable

\section{E. Implementasi}

Berdasarkan instalasi dan konfigurasi sistem yang telah dibangun, berikut ini merupakan beberapa tampilan output sistem yang berhasil dibangun.

\section{- Tampilan Antarmuka File Sharing}

Halaman antarmuka file sharing dapat digunakan untuk berbagi pakai dokumen antar pengguna yang berhasil terhubung ke router. Dengan demikian, apabila pengguna berada pada ruang lingkup sesuai dengan area yang dapat dijangkau router, maka tidak perlu repot-repot bertukar file menggunakan flashdisk, tetapi cukup dengan mengunggah file melalui aplikasi ini. Berikut ini merupakan tampilan antarmuka file sharing sesuai dengan gambar 3 .
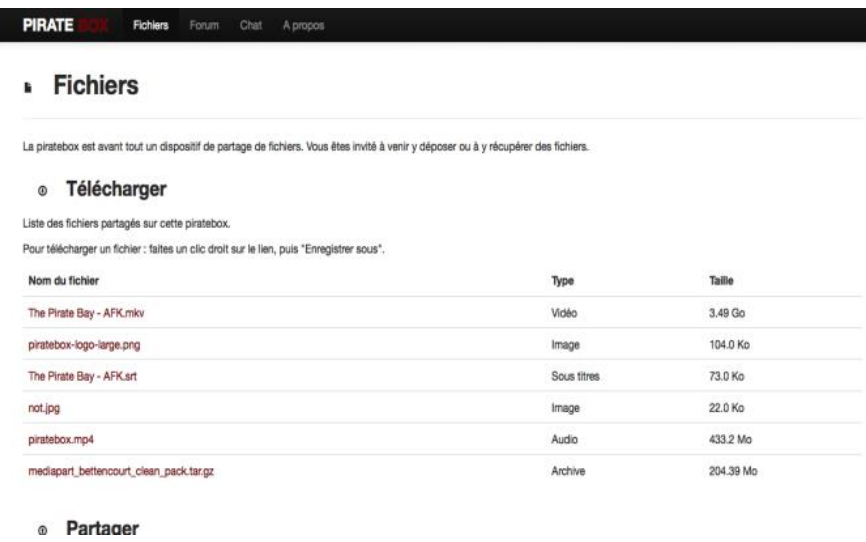

Gambar 3: Antarmuka File Sharing

Pengguna yang sudah terhubung ke router, dapat berbagi dokumen apapun ke dalam sistem yang dibangun. Adanya fitur ini diharapkan dapat memperlancar aktivitas belajar mengajar civitas akademika Universitas Muhammadiyah Jember.

- Tampilan Antarmuka Chatting

Antarmuka chatting digunakan untuk bahan diskusi antar pengguna yang sudah terhubung ke router. Pengguna chatting boleh melakukan custom nama yang terdapat pada screen chatting. Berikut ini merupakan tampilan dari antarmuka chatting seperti ditunjukkan pada gambar 4.

\section{PIRAT}

- Chat

18:20283 anonymous: Plop

18:20:28 anonymous: Plop
00:00:00 PirateBox: Chat and share flies anconymousy!

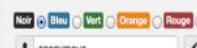 \\ 1 amorynous $\quad 1$ vatro ien}

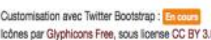

Gambar 4: Antarmuka Chatting

Pada gambar tersebut, antarmuka chatting dapat digunakan untuk berkomunikasi antar pengguna. Pengguna dapat melakukan customisasi dari username, warna, dan pesan yang akan dikirimkan.

\section{F. Pengujian}

Pada gambar tersebut, antarmuka chatting dapat digunakan untuk berkomunikasi antar pengguna. Pengguna dapat melakukan customisasi dari username, warna, dan pesan yang akan dikirimkan.

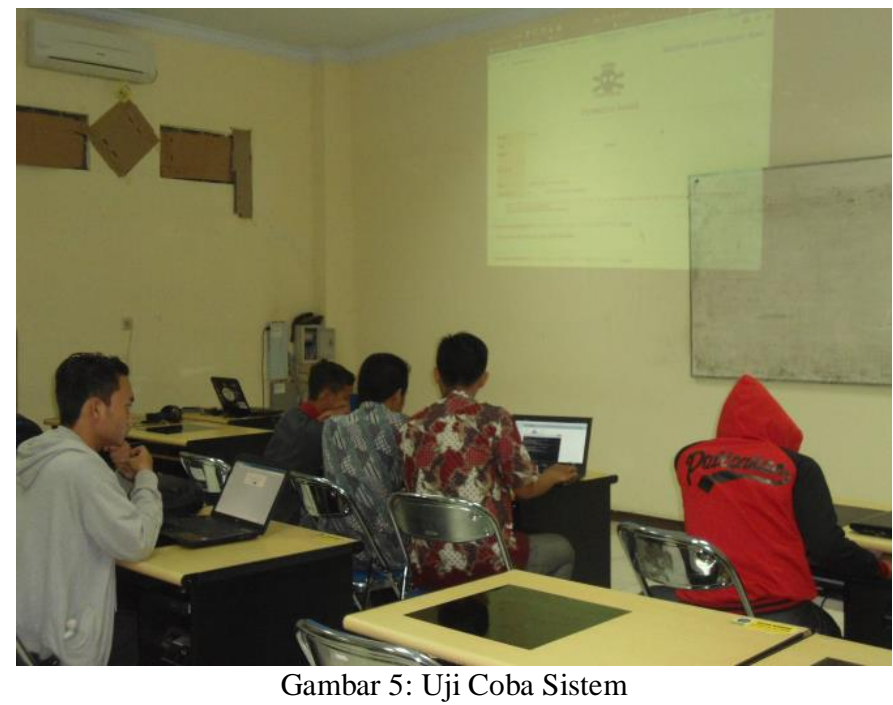

Uji coba dilakukan untuk menguji fitur dan kemudahan penggunaan sistem. Berdasarkan gambar tersebut, terlihat bahwa beberapa civitas akademika terlihat mudah dalam menggunakan sistem smart router ini. 


\section{A. Kesimpulan}

Berdasarkan penelitian yang sudah dikerjakan, dapat disimpulkan beberapa aspek sebagai berikut :

- Router TP-Link MR-3020 yang sebelumnya mempunyai firmware bawaan pabrik yang hanya dapat menangani berbagi konektivitas saja, dapat ditingkatkan penggunaannya dengan mengubah firmware-nya menggunakan OpenWRT dan Piratebox.

- Penggunaan firmware OpenWRT dapat meningkatkan fungsionalitas router, menjadi router yang dapat menangani fungsi yang berbeda daripada firmware bawaan pabrik, diantaranya berbagi dokumen, chatting, dan forum.

- Fitur yang dihasilkan dari smart router tersebut dapat digunakan dengan mudah oleh civitas akademika Universitas Muhammadiyah Jember karena mempunyai tampilan yang user friendly.

- Media chatting dan file sharing yang terdapat pada firmware dapat mengurangi penggunaan flashdisk di lingkungan laboratorium.

\section{B. Saran}

Saran yang dapat dituliskan oleh penulis, supaya dapat dikembangkan lagi oleh peneliti selanjutnya, diantaranya:

- Sistem yang dibangun berdasarkan firmware OpenWRT dan Piratebox masih terdapat kendala yaitu sering terjadi hang apabila pengguna yang mengoperasikan terlalu banyak. Pada penelitian selanjutnya diharapkan dapat memperbaiki kekurangan sistem tersebut.

- Sistem yang dibangun berdasarkan hardware router TPLink MR-3020 hanya dapat mencakup beberapa ruangan saja, diharapkan pada penelitian selanjutnya dapat dibangun dengan hardware yang mumpuni, sehingga cakupan sinyal wireless dapat terjangkau di seluruh wilayah Universitas Muhammadiyah Jember.
[1] T. A. Cahyanto, V. Wahanggara, and D. Ramadana, "Analisis dan Deteksi Malware Menggunakan Metode Malware Analisis Dinamis dan Malware Analisis Statis," JUSTINDO, vol. 2, no. 1, pp. 19-30, 2017.

[2] T. A. Cahyanto, "Analisis deteksi penyusupan pada jaringan komputer menggunakan snort (studi kasus pada Dinas Pariwisata Propinsi Daerah Istimewa Yogyakarta)," Yogyakarta, 2011.

[3] T. A. Cahyanto, H. Oktavianto, and A. W. Royan, "Analisis dan Implementasi Honeypot Menggunakan Dionaea Sebagai Penunjang Keamanan Jaringan," JUSTINDO (Jurnal Sist. dan Teknol. Inf. Indones., vol. 1, no. 2, pp. 86-92, May 2013.

[4] T. A. Cahyanto and Y. Prayudi, "Investigasi Forensika Pada Log Web Server untuk Menemukan Bukti Digital Terkait dengan Serangan Menggunakan Metode Hidden Markov Models," SNATi, pp. 15-19, 2014.

[5] Asriadi, I. Pratomo, A. Affandi, and D. S. Rahardjo, "OpenVoice: Low-Cost Mobile Wireless Communication Project For Rural Area Based on OpenWRT," in 2015 International Seminar on Intelligent Technology and Its Applications (ISITIA), 2015, pp. 391-396.

[6] C. E. Palazzi, M. Brunati, and M. Roccetti, "An OpenWRT Solution For Future Wireless Homes," in 2010 IEEE International Conference on Multimedia and Expo, 2010, pp. 1701-1706.

[7] R. N. Hidayat, "Implementasi Tomato Firmware Pada Linksys Wireless Router Dengan Proses Authentification, Authorization, Accounting Menggunakan Radius Server," Semin. Nas. Apl. Teknol. Inf. Faks, vol. 122, 2010.

[8] R. I. Sulistiyawati, W. A. Syafei, and I. Santoso, "Rancang Bangun Jaringan Printer Nirkabel Menggunakan Wireless Router TL-MR3420V2 dan OpenWRT," vol. 17, no. 1, pp. 14-19, Jan. 2015.

[9] I. Gunaro, "Pengembangan Script Instalasi Dan Konfigurasi Samba Server Pada OpenWRT 12.09 Attitude Adjustment," Apr. 2015.

[10] T. Cahyanto, "BAUM-WELCH Algorithm Implementation For Knowing Data Characteristics Related Attacks On Web Server Log," in PROCEEDING IC-ITECHS 2014, 2015.

[11] R. S. Pressman, Software Engineering: A Practitioner's Approach. McGraw-Hill, 2005. 